\title{
Esporte e política na ditadura militar brasileira: a criação de um pertencimento nacional esportivo
}

\author{
Marcus Aurelio Taborda de Oliveira*
}

\begin{abstract}
Resumo: No trabalho percorro indícios da relação entre esporte e política durante o período da ditadura que assolou o Brasil nas décadas finais do sec. XX. Distancio-me de explicações conspiratórias, e problematizo o fato de o fenômeno esportivo, marca da universalização da cultura, ter servido ao propósito político da ditadura, sem que tenha sido ela o seu propulsor. Antes, argumento que a ditadura soube ler o contexto mundial para apropriar e difundir uma pratica de grande apelo de massas e consumo, que remeteu a novas formas de subjetivação, afetando, assim, os interesses e as necessidades de grandes parcelas da população brasileira. Tomo como fontes, alem de documentos próprios do universo esportivo, rastros do debate sobre o nacional e o popular, marca do que foram as tentativas de afirmação da nação.
\end{abstract}

Palavras-chave: esporte e ditadura militar; esporte e política; nacional e popular; cultura de massas.

A fome, a doença, o esporte, a gincana.

A praia compensa o trabalho, a semana.

O chope, o cinema, o amor que atenua

o tiro no peito, o sangue na rua.

A praia a doença, não sei mais porque...

Que noite, que lua, meu bem, pra que?

Sidney Miller

Revisitar o tema das relações entre esporte e poder político, este de caráter autoritário, é sempre um desafio que exige articular

\footnotetext{
"Bolsista em Produtividade do CNPq, Coordenador do NUPES - Núcleo de Pesquisas sobre a Educação dos Sentidos e das Sensibilidades, Universidade Federal de Minas Gerais, Belo Horizonte, MG, Brasil. E-mail: marcustaborda@uol.com.br
} 
diferentes escalas de análise. Por um lado, porque cada formação social apresenta suas próprias vicissitudes, suas maneiras próprias de articular política (poder) e cultura, representada pelo esporte, pela educação, pela arte, por distintas formas de pensamento etc. Por outro lado, porque a relação entre formas de dominação e usos da cultura são, provavelmente, uma das marcas mais tangíveis do espírito humano, assumindo contornos imemoriais. No entanto, é difícil sustentar que o esporte, fenômeno tipicamente moderno, apenas atualizaria aquele impulso humano de dominação. Isso significaria reduzir de maneira simplista a complexidade não só do esporte e da política, mas também da cultura a um jogo "dominantes x dominados" bastante conveniente para os apologistas das teorias da conspiração. Antes é preciso focalizar o contorno que cada manifestação da cultura assume em determinado tempo e lugar, para que possamos, particularizando a análise, dimensionar os seus usos pelo poder político, seja aquele de caris democrático ou aquele que tem no autoritarismo e no totalitarismo sua máxima expressão considerando, ainda, como a política se articula com o mercado, com a mídia, com a tradição, com os intelectuais e com idéias tais como liberdade, direitos, justiça, igualdade, democracia etc. Isso nos faz pensar na articulação entre política e esporte na produção da "brasilidade" (ou da argentinidad, ou da hispanidad...) e temas tais como cultura política, identidade nacional, propaganda, relações internacionais, políticas públicas, e sua relação com formas autoritárias de manifestação política, tais como conheceu o Brasil em diferentes momentos da sua história. Assim, procurarei percorrer um momento da história política brasileira marcada por uma política de exceção, a ditadura militar (1964-1985), e a presença do esporte como fenômeno cultural naquela ambiência, tomando como referência dois momentos específicos. O primeiro, imediatamente após a realização das Olimpíadas de Munique, em 1972. O segundo, 10 anos depois, quando a ditadura já estava nos seus estertores. Espero que, ao final de texto, meus argumentos possam convencer o leitor do acerto das minhas escolhas. 


\section{Are-InVenção da naÇão: nenhuma novidade no céu do meu Pá́s}

Ainda que Homi Bhabha (1998) proponha a análise da nação como um entre-lugar, como margem às formas eurocêntricas de conceber a construção da nação e da nacionalidade, parece forçoso reconhecer que os apelos à construção da nação brasileira, à direita e à esquerda, foram desenvolvidos a partir de matrizes claramente eurocêntricas. Assim, não deve estranhar que o período da ditadura brasileira pós-64 fosse marcado por um debate sobre o que seria o "nacional autêntico", aquele genuinamente popular ou àquele associado com iniciativas e modelos internacionais. Mais que apenas expressar o teor das próprias teorias do desenvolvimento em voga desde os anos 1950, esse debate expressava uma ânsia pela afirmação do Brasil (e da brasilidade) em um mundo marcadamente "nacionalista", no qual a auto-estima de um país passava, necessariamente, pela afirmação do seu espírito (e das realizações deste) na arena dos embates internacionais, mesmo que se tratasse, no caso brasileiro, de uma operação do tipo nacional por subtração, como postula Schwarz (2001). Esses embates assumiam o caráter bélico em múltiplas ocasiões, como não deixam dúvidas os enfrentamentos militares no sudoeste asiático, no Oriente Médio, na África e na América Latina, envolvendo diretamente grandes potências militares, mas também assumiam formas na tática de guerrilhas e no terrorismo, expressos em absolutamente todos os lugares do planeta, incluída a Europa.

Mas essa forma de afirmação da auto-estima de uma nação corria paralela à outra, aquela que procurava (e ainda procura) capturar a "sensibilidade das massas" em um esforço de afirmação política que lançava mão da cultura - e da sua propaganda - como veículo para a produção de uma identidade comum. Mobilizava-se, assim, a música, o teatro, o cinema e o esporte como elementos fundamentais na afirmação de uma ou de outra expressão do que seria "verdadeiramente" brasileiro. Se os poderosos de antanho mobilizavam os jornais, a TV, o rádio e os espetáculos esportivos para afirmar o espírito nacional desejado pela ditadura, não é menos verdade que os Teatros Arena e Oficina, que os CPCs da UNE, que 
as CEBs, que os festivais da canção, que iniciativas como as de Ênio Silveira e sua Civilização Brasileira, todas iniciativas particulares de afirmação da cultura, também ocupavam intensamente a cena política propondo alternativas ao modelo civil-militar imposto pela ditadura, ainda que também o fizessem em nome da afirmação do que era nacional. Na verdade, a tensão entre o nacional e o internacional, ou universal, como intuía Mario de Andrade, recuperado por Sidney Miller (1968), dava o tom dos debates sobre o papel político que a cultura assumia na organização da vida nacional brasileira. Definir, a priori, o que era conservador, reacionário, progressista ou revolucionário naquele debate só pode ser feito nos termos do próprio debate, e não como recuperação de um passado heróico, de uma tradição de lutas e resistências, que tão bem contribui para afirmar uma só idéia do que seria o "Brasil original", o nacional "autêntico", ou o "verdadeiro" espírito nacional.

Assim, pois, a "legitimidade" das formas de afirmação política da ditadura, e a sua contraparte expressa em distintos movimentos de resistência, só podem ser percorridos no entendimento da própria forma de organização política da sociedade brasileira, de forte acento conservador e centralizador, sem que tenha se abstido de cores modernizadoras e nacionalistas. Essas formas têm seus pressupostos lançados ainda no século XIX, percorrendo um longo percurso que embaralha o público e o privado, que faz crer que o usufruto daquilo que é necessariamente público pode ser particularizado, individualizado como, de fato, nossa formação social acabou assimilando no seu dia-a-dia. Não me parece que as idéias tenham estado fora do lugar, como propôs Schwarz, mas elas expressam, justamente, as formas "originais" que a cultura e a política assumiram no Brasil. Sem considerar que uma temporalidade homogênea tenha definido a relação entre cultura e política no Brasil, ainda assim é factível reconhecer que como síntese de uma determinada tradição seletiva (WILLIAMS, 2005) o advento da ditadura brasileira realiza uma forma autoritária que expressa muito da própria cultura política brasileira, da qual fazem parte todos aqueles que procuraram, por vias diversas, a afirmação do nacional, seja de matiz popular ou de elite. Pois a produção do sentido ou do sentimento nacional, por si 
só, percorre um modelo de padronização cultural que diz menos sobre o que significam a polissemia e a polifonia da diferentes "culturas brasileiras", multiplicidade apagada por quaisquer tentativas de unidade ou identificação, sintoma claro de formas autoritárias de organização política ou cultural, a despeito da retórica progressista que as possa fundamentar. Se esse é um pressuposto do nacionalismo tal como o temos concebido no âmbito do nosso pensamento social, herdeiro de uma expressão da "modernidade ocidental", imagine-se o que significa esse postulado para um regime ditatorial.

Não seria o esporte, como fenômeno da cultura, a escapar dessa lógica. Talvez a sua particularidade no período esteja no reconhecimento do fato de ser, indiscutivelmente, um fenômeno universal e universalizado. Pois, se a música, o teatro, a literatura e o cinema podem ser reconhecidos como fenômeno universal, os agudos manifestos pela afirmação de uma cultura genuinamente nacional faziam crer que a inscrição do Brasil no âmbito internacional deveria ocorrer pela sua capacidade de dar a ver o Brasil "autêntico", a criatividade brasileira "genuína", a "inventividade" de um espírito que não queria ser margem, mas reconhecido como algo singular no universo da criação cultural universal. Já reconhecido o esporte como fenômeno universal de massas, afeito à padronização, caberia dar a ele um tratamento que permitisse o Brasil destacar-se no cenário internacional pela sua "potência" e "força", pela sua capacidade de competir em igualdade - que almejava a superioridade - na arena internacional, pela sua capacidade de superar desafios no enfrentamento dos seus problemas externos ou internos.

\section{1972: CULPADOS E INOCENTES}

Ainda que apenas dois anos antes o Brasil trouxesse definitivamente do México a Taça Jules Rimet, no balanço do resultado alcançado pelo país nas Olimpíadas de Munique não há margem para qualquer sentido de ufanismo, tal o tom manifesto por algumas das principais autoridades esportivas do país. Se o futebol representava um grande reconhecimento do país no plano 
internacional, o esporte como um todo estava longe de permitir que o Brasil Grande saísse do ideário oficial e ganhasse o mundo. Se 90 milhões eram convocados à ação pelo ufanismo musical e oficial, o resultado das Olimpíadas de 1972 não deixava margem para dúvidas: naqueles Jogos o Brasil acabou em $41^{\circ}$. lugar, junto com a Etiópia, com duas medalhas de bronze. Era muito pouco, não para um país, mas para um regime que apostava na megalomania como agente de educação das massas e conseqüiente engrandecimento da nação.

Fazendo apologia da política da ditadura para os esportes, enaltecendo a realização do Diagnóstico da Educação Física e Desportos no Brasil de 1971, prometendo a efetivação de um Plano de Educação Física e Desportos para o país, o editorial do número 12 da Revista Brasileira de Educação Física e Desportos, revista oficial, assinado por Eric Tinoco Marques, não por acaso se intitulava O tempo de colher. Segundo o autor, diretor do Departamento de Educação Física e Desportos do então Ministério da Educação e Cultura, o conjunto de realizações do "governo revolucionário" no âmbito desportivo era motivo mais que suficiente para que fosse possível, em pouco tempo, exigir resultados dos professores de Educação Física brasileiros. Pois se aquelas iniciativas oficiais de apoio ao esporte, aí incluída a Campanha Nacional de Esclarecimento Esportivo, marcavam um "tempo de produzir" oportunizado pela ditadura, então "amanhã será tempo de colher" (MARQUES, 1972, p. 4). Para tanto, os professores eram convocados a participar das iniciativas do periódico e do governo militar no âmbito das políticas públicas para o esporte, não apenas cedendo o seu apoio a tais iniciativas, mas atuando de forma efetiva no engrandecimento esportivo do país. Falava-se aos professores como companheiros de viagem, como parceiros potenciais na criação de um sentimento comum daquela nação "que ia pra frente", como se as políticas daqueles anos tivessem, de alguma maneira, algum grau de participação democrática ou popular. Aliás, não era incomum que civis e militares alinhados reivindicassem a democracia para justificar o perigo do comunismo e da subversão, em uma operação discursiva que pretendia fazer crer que a exceção se tratava de um acidente normal da ars politica. 
Ainda naquele mesmo número, Ovídi Souza escrevia um artigo intitulado Munique 72: culpados e inocentes. Se o título sugere ao leitor alguma referência ao massacre perpetrado pelo grupo terrorista Setembro Negro, no dia 05 de setembro de 1972, durante a realização das Olimpíadas de Munique, nada mais enganador. O autor faz, na verdade, em um texto recheado de imagens enaltecedoras daquela edição dos jogos, inclusive selos alusivos aos mesmos, um diagnóstico da pífia participação brasileira na competição. O tom do seu texto é aquele já bem conhecido: enaltecimento das realizações da ditadura militar em relação a um passado de incúria e abandono do esporte nacional, o qual fora retratado no aludido Diagnóstico de 1971. Assim, ao tecer com acurada precisão as causas do "fracasso" brasileiro, o autor reedita uma das forças da tradição do pensamento social brasileiro, justamente aquele que pretende, se não apagar o passado, identificá-lo com o arcaico, o atraso, com o velho.

Entre os inúmeros culpados pelo fracasso esportivo brasileiro encontramos o analfabetismo, o déficit habitacional, a precária educação sanitária, o déficit nutricional decorrente de uma alimentação pobre e uma previdência social em desacordo com os "novos tempos". Esses culpados, frutos de "um processo secular", estavam em vias de serem superados pela pujança da política implantada pelos governos militares. A alternativa, claro está, seria a invenção do novo - pois é de invenção que se trata no plano discursivo - motivo pelo qual o autor se jactava ao declarar: "Felizmente, para júbilo dos brasileiros, o Governo Revolucionário já vem adotando providências que darão nova estrutura e meios à política nacional da Educação Física e dos Desportos" (SOUZA, 1972, p. 16). O modelo referido pelo autor era a "América do Norte, de nós a mais próxima e que nos tem servido de modelo evolutivo em muitos aspectos" (SOUZA, 1972, p. 14).

Em uma operação no mínimo curiosa, o autor reconhecia a própria falência do Estado e da sociedade brasileiros na superação dos seus problemas mais elementares. No entanto, o remédio para aquele estado de coisas, cuja culpa se localizava em algum lugar do passado, era a ação determinada da ditadura na organização de uma 
reforma das práticas desportivas, projeto para o qual eram convocadas as escolas brasileiras e os professores de Educação Física. Ou seja, ao invés de o esporte aparecer como uma decorrência de índices de desenvolvimento sócio econômico que significassem também redistribuição de renda, por exemplo, ele aparecia como o motor do desenvolvimento. Sem uma ação enérgica a nação não poderia ser energética. Sem uma cultura da ação que mobilizasse o cidadão brasileiro para uma atuação efetiva em prol daquilo que é "nacional" não seria possível superar os graves problemas sócio-econômicos que vivia o Brasil. Assim, não estranha que a propaganda oficial se esfalfasse para calar em corações e mentes bordões como Brasil, ame-o ou deixe-o!, Esse é um país que vai pra frente!, ou recuperasse uma já não tão nova idéia de Ama, com fé e orgulho, a terra em que nascestes!, e desse um caráter universal (nacional) e espetacular ao jogos entre escolares, como aquele que se conheceu com o advento dos Jogos Escolares Brasileiros.

A propaganda, por certo, é um dos grandes motores da política, explodindo o seu uso em regimes autoritários ou totalitários. No caso brasileiro, além de a ditadura ter fomentado de forma avassaladora a distribuição de concessões públicas de rádios e televisões, ela ainda ocupava boa parte da mídia com a divulgação das suas realizações, tivessem ou não correspondência com a verdade, caracterizando um espaço de veiculação de um veio discursivo tido por "competente" (CHAUÍ, 1981), altamente legitimador e de grande apelo junto às massas. Assim, pois, a apropriação da vitória do futebol brasileiro nos gramados mexicanos em 1970 é sintoma de uma operação que pretendia menos amainar os ânimos "revolucionários", como muito se supôs, e mais dotar um "povo" - algo já genérico, de invenção relativamente recente - de uma unidade de sentimentos brasileiros na arena política internacional. Se nas primeiras décadas do séc. XX se procurou construir a idéia de um "povo brasileiro", nos tempos da ditadura esse povo era, além do mais, um "vencedor". A retórica do esporte, com seus índices, recordes, e histórico de superações cabia como uma luva nas mãos de militares e grupos dominantes civis. 
Ainda que não se deva esquecer que o esporte teve grande desenvolvimento também pela via militar e faz parte da tradição da caserna, a segunda metade do séc. XX assiste a proliferação do esporte como fenômeno de massas em todo o mundo. Parece lógico que, a despeito da coloração autoritária do regime, o Brasil também se valesse desse fenômeno para afirmar-se como potência planetária. Trata-se do desenvolvimento de uma sensibilidade para aquilo que é nacional, brasileiro, com resultados que podemos aferir ainda hoje, quando somos levados a confundir qualquer indivíduo que seja atleta e apareça na televisão com as mais "nobres" causas nacionais, como se o desempenho esportivo de uns poucos significassem a dignificação da vida de todos.

Assim, pouco importava a uma revista oficial se a ideologia do olimpismo sofrera um duro golpe com os atentados de 05 de setembro de 1972, em Munique. Tratava-se de fomentar o esporte como vetor do desenvolvimento brasileiro, como via imediata de identificação entre regime, povo e governo, acima das diferenças entre indivíduos, grupos, classes. Pois o sucesso de um era, na verdade que se pretendia veicular pela mídia, o sucesso de todos e, sobretudo do demiurgo que constituía a "nação", mesmo que verdade e política estejam longe de serem parceiras fiéis (ARENDT, 2003). Pouco importava clamores como os de Erich Fromm (1967, p. 83), traduzido por Enio Silveira, que asseverava: "Temos que evitar a todo custo que nos transformemos numa nação de Eichmanns, para quem a ordem e a organização sejam valores mais altos do que a vida e o progresso". O que estava em jogo era o Brasil-potência e para a sua realização o fantasma do carrasco parecia percorrer os porões da ditadura.

Inventar um passado condizente com os anseios de um determinado poder é uma forma consagrada de operação de convencimento das massas (RANGER; HOBSBAWM, 1997). Como se partia do pressuposto que o Brasil melhoraria também pelo esporte, e que este precisava sofrer um choque de modernização, se reiterava que a reforma da cultura pela via do esporte representava a própria possibilidade de reforma do sentimento nacional. Com a 
potencialização da mídia esportiva, iconicamente representada pelo Canal 100, sempre apologética dos grandes feitos e heróis, não parecia difícil que uma campanha agressiva como a Campanha Nacional de Esclarecimento Esportivo reverberasse em todos os cantos de país, produzindo um discurso homogêneo e aparentemente sem fissuras sobre o gigante adormecido que acordava para o momento da sua grandeza no cenário mundial. Não por acaso, a parceria entre o Departamento de Educação Física e Desportos do MEC e a Editora Abril, produzia um jornal mensal com o sugestivo nome de Podium, que tinha como subtítulo o dístico Jornal do Professor de Educação Física. Não somente o governo militar, mas também significativas parcelas da sociedade civil, sobretudo a grande imprensa, queriam fazer crer que o esporte era condição básica da modernização social e pairava acima das diferenças políticas que, em qualquer democracia significam a própria oxigenação da vida pública, mas no Brasil e na maior parte do mundo dito "periférico", faziam daqueles anos, anos de exceção, arbítrio e violência. O pódio, talvez o símbolo máximo da cultura esportiva, era bastante apropriado para uma cultura política autoritária que pretendia estar no topo, à frente, no ápice. A ditadura não inventou o esporte. Mas ele parece feito sob medida para fomentar um conjunto de símbolos que remetiam à eficiência, ao desempenho, à vitória, à superação, à ação, temas recorrentes no léxico da sociedade brasileira daqueles anos, sob a batuta dos militares. $\mathrm{O}$ enfrentamento à subversão se fazia à bala, tortura e morte. $\mathrm{O}$ esporte cumpria um papel menos físico ou atlético, e mais simbólico. Menos anestésico das consciências e mais fomentador de sentimento comum de pertencimento. Pretendia-se fazer crer que aqui existia uma só nação. Não se tratava do serviço militar obrigatório, da obrigatoriedade do voto ou da correção no uso da língua comum. Antes, a união desse "povo que não desiste nunca" vinha pela pretendido auto-reconhecimento que o "verde, amarelo, azul e branco" compunham as cores do nosso vitorioso lugar no mundo. Assim, o esporte no seu amálgama com a política funcionava duplamente naqueles anos: por um lado, contribuindo para o cimento da coesão, harmonia e alegria nacionais, ajudando a consolidar o "brasileiro" como um vencedor; por outro, contribuindo para refinar 
a presença do Brasil nos trilhos do progresso, da riqueza e da modernidade. Afinal, o Brasil se apresentava aos olhos do mundo incorporando alguns dos símbolos da "globalização" da cultura, como o shopping-center, a cultura pop, e o esporte, não por acaso, pedra de toque das políticas mundiais da UNESCO.

\section{ANOS 80: A CONSTRUÇÃO DE UM ESPÍRITO ESPORTIVO NACIONAL COMUM}

Sabemos através das páginas da Revista Brasileira de Educação Física e Desportos - RBEFD, que no começo da década de 1980 o governo brasileiro dava um novo impulso à política esportiva nacional. Não se enaltecia mais as realizações dos governos militares, mas se falava das conquistas do país no plano cultural e esportivo. O país era a unidade desejada pelos militares, pelo menos em retórica.

Para além do governo e dos militares, novos agentes eram convidados - não mais convocados! - a participar do engrandecimento não só esportivo do país. Da pena do ministro da Educação e Cultura, Rubem Ludwig, foi aprovada a portaria 522, que definia o novo regimento da Secretaria de Educação Física e Desportos (SEED) do MEC. Entre outras coisas, aquele ato legal definia a prioridade do Esporte para Todos (EPT) na política nacional "visando a atender o aprimoramento da aptidão física da população e a implementação da prática dos desportos de massa" (EDITORIAL..., 1981, p. 46). Além daquela prioridade, o chamado desporto escolar e a formação de quadros especializados no exterior ganhavam destaque na política daquele órgão. É de se destacar, ainda, o investimento de "mais de Cr\$ 5 milhões em passagens aéreas", para as confederações de atletismo, pentatlo moderno, motociclismo, natação, pólo aquático, tiro ao alvo e xadrez" (EDITORIAL..., 1981, p. 47). O layout da revista, naqueles anos, estava em acordo com um novo momento da vida nacional. Não só no que se refere à sua qualidade material, mas também a modernização da sua linguagem em termos editoriais denotam um processo de abertura do Estado para as necessidades do mercado. Assim, aquele periódico oficial que 5 anos antes se 
apresentava quase que como um manual produzido de forma precária, ganhava uma apresentação bastante atualizada para os padrões editoriais daqueles anos. Além disso, a tiragem de 2 mil exemplares do início da década de 1970, pularia para 50 mil em 1981 e 100 mil exemplares, em 1983, sempre com distribuição gratuita, dando uma mostra do incremento do campo esportivo no Brasil.

O Estado, já em tempos de abertura política, também se abria para as parcerias com a iniciativa privada no fomento ao esporte. Assim, observa-se uma propaganda agressiva de grandes grupos econômicos, de seguros a combustível, passando por automóveis e conglomerados editoriais, nas páginas da revista, sempre associadas à sua contribuição para o engrandecimento do esporte nacional. Se dez anos antes o esporte parecia ser o lenitivo para os graves problemas do país, e o governo assumia que era o grande responsável pelo seu incentivo, nos anos 1980 o tom era outro. Em uma fala pronunciada junto à Confederação das Associações Comerciais do Brasil, recuperada pelo editorial da RBEFD, o ministro da Educação e Cultura, Rubem Ludwig, defendia que era preciso que a comunidade participasse da construção das políticas culturais - entre elas a educação e o esporte - em "face da escassez de recursos que ocorre em nações como o Brasil, em fase de desenvolvimento" (EDITORIAL, 1981, p. 1, grifos meus). Dizia: "Vejo a formulação e a execução da política nacional de educação e cultura como um campo aberto à participação e até mesmo como um compromisso de todos, à medida que a educação é parte essencial do esforço nacional na busca de soluções para os problemas sociais e econômicos do país" (EDITORIAL, p. 1, 1981). Na sequência, o editor daquele número rematava: "Estas considerações nos levam a creditar à iniciativa privada algumas das contribuições eficazes à educação em nosso país, inclusive, no que diz respeito à educação física e ao desporto" (EDITORIAL, 1981, p. 1).

Em nome da criatividade da iniciativa privada, e do compromisso de todos com a construção de um país melhor, a Secretaria de Educação Física e Desportos anunciava os "novos tempos" da política brasileira para o setor: a parceria entre o Estado e o grande 
empresariado no fomento ao esporte. Estava encerrada a fase de centralização e de protagonismo do Estado na gestão dos assuntos relativos ao esporte. Incentivava-se o fortalecimento das confederações, evocava-se o entendimento nacional para projetar o desenvolvimento esportivo. O Estado centralizador, autoritário, viase diante do constrangimento de assumir o seu fracasso no cumprimento de metas estabelecidas uma década antes. O Brasil não se tornara uma potência esportiva, a escola não se tornara um celeiro de atletas. Mais: grassava a pobreza, a má distribuição de renda, o analfabetismo e índices pífios de rendimento escolar. Ou seja, o milagre econômico do início da década de 1970 começava a mostrar a suas conseqüências nefastas. A ditadura cambaleava premida pelas manifestações da sociedade civil e apelava à sociedade para que assumisse uma cruzada contra o subdesenvolvimento, termo caro àqueles anos. O Estado propunha a partilha das responsabilidades pelo fomento da educação, da cultura e do esporte no Brasil, ainda que saibamos que é dos cofres públicos que sai o maior investimento direto ou indireto para o esporte nacional, sempre sem a devida contrapartida dos chamados "parceiros" privados. Como um réquiem, os apelos do ministro, do editor e da Revista indicavam claramente que o Brasil não crescera como prognosticava a política dos governos ditatoriais dos anos 60 e 70.

No plano da definição de uma sensibilidade esportiva, o que se viu foi o incremento do esporte de alto-rendimento em escala nunca antes vista. Naqueles anos iniciou-se no Brasil uma agressiva sensibilização para a prática de atividades esportivas por parte da população, além de se ter estimulado a formação de "platéias" e "audiências" esportivas. Não só o futebol granjeava torcedores, mas os tradicionais clubes passaram a dar lugar a equipes que levavam e levam - o nome de grandes corporações empresariais. E vimos nascer o fenômeno das torcidas por uma marca de desodorante ou de botijões de gás, fenômeno que explodiria na década seguinte. $\mathrm{O}$ governo militar retirava-se da cena esportiva e convocava a sociedade - leia-se, iniciativa privada - para assumir os encargos do fomento do esporte no Brasil. Em um setor periférico da política de Estado, podemos localizar o prenúncio das políticas públicas da 
década de 1990, com a tentativa de estabelecimento de um "estado mínimo", dirigido pela "mão invisível do mercado". Talvez devamos nos perguntar, do ponto de vista do estabelecimento de políticas públicas, se os governos militares até, pelo menos 1979, quando assume a presidência João Batista Figueiredo, não representavam um esforço diretor menos promíscuo em relação à participação privada no âmbito do Estado. É possível ver hoje, por exemplo, a promiscuidade como um absurdo de recursos públicos são mobilizados em prol do esporte de alto-rendimento, sem que isso reverta em qualquer benefício para a maior parte da população brasileira. Os recentíssimos exemplos da preparação para a Copa do Mundo de 2014 e os Jogos Olimpicos de 2016 o atestam.

Naquele início do fim da ditadura militar, se mudava o tom em relação às políticas esportivas, mesmo o tom ufanista era matizado. Não se precisava mais apelar para o engrandecimento do Brasil, ainda que o apelo nacionalista permanecesse nas mais diversas falas, como aquela de um destacado jogador de futebol que chegou ao ponto de falar em uma manifestação pelas Diretas, já! que não se transferiria para o futebol europeu se as eleições diretas fossem aprovadas no Brasil. Ou seja, outra marca da tradição política brasileira, o populismo, que se entrincheira à esquerda e à direita, calava fundo no imaginário daqueles anos finais da ditadura militar brasileira denotando o quanto é possível confundir-se a dimensão pública que encerra a política, com os anseios particulares de grupos, indivíduos ou classes.

O novo momento político, no qual os militares perdiam espaço, no que se refere às políticas públicas para o esporte era grande o incentivo ao chamado esporte de massa ou comunitário, aquele que se situa, no imaginário de muitos, entre o esporte escolar e o esporte de alto-rendimento, já preconizado em um número especial da RBEFD, cinco anos antes. Em tese, trata-se de uma forma de conceber a atividade física e esportiva como um dos motores do capital humano que qualificaria a população para a crescente complexidade dos postos de trabalho, além de dotá-la de condições 
de usufruir de forma "equilibrada" do seu tempo livre, duas grandes ficções em um país onde ainda se conhece o trabalho escravo e que tem uma das menores massas salariais do planeta.

Assim, na senda das políticas internacionais para o esporte, estimuladas, sobretudo, pela UNESCO, o governo brasileiro promoveria uma política que procuraria desenvolver um "estilo de vida ativo", através do estímulo da prática esportiva permanente pela maior parte da população, na tentativa de inventar uma qualidade de vida negada pelas absurdas desigualdades - econômica, política, cultural, social - que marcam a organização da sociedade brasileira. Dando continuidade a iniciativas da década anterior, muito se falou sobre a educação física e o esporte na escola e iniciativas como colônias de férias, ruas de lazer, festivais de verão, entre outras tantas que visavam oportunizar a qualquer pessoa comum a prática de algum tipo de atividade física, de cunho esportivo ou não. Entre um estado paternalista e os primeiros ventos do chamado neoliberalismo no mundo, com as experiências Margareth Tatcher, na Inglaterra, e Ronald Reagan, nos Estados Unidos, o Brasil parece ficar a meio caminho entre a construção de um Estado de corte liberal e a sua tradição política de forte apelo compensatório e assistencialista.

O que a década da constituição redentora, assim como os anos de chumbo mostraram, é que a política no Brasil sempre se fez em consonância com os desejos de manutenção de uma ambigüidade básica: um dos países mais ricos do mundo com uma massa miserável sem condições de prover a sua própria subsistência ${ }^{1}$. Quadro perfeito para a manutenção dos jogos de poder marcados pela esterilidade retórica e pela explosão de políticas assistencialistas, no qual o grande papel do estado é gerenciar o capital privado que se multiplica nas suas próprias entranhas. Nessa ambiência a indústria esportiva explode também aqui, assim como a presença do esporte na mídia e na indústria de entretenimento.

\footnotetext{
'Dados recentes das Nacoes Unidas revelam que o Brasil, que se jacta de ser a sexta economia do planeta desde há alguns anos, e o quarto pais mais desigual da America Latina, atrás apenas de Guatemala, Honduras e Colombia.
} 
O saldo que pode ser aferido dessa política é a realização, de fato, de um sentimento esportivo em parte bastante significativa da população brasileira. Afinal, se não é possível afirmar que este é um país de praticantes do esporte, não se pode negar que o seu apelo midiático, logo, econômico, é monstruoso. Se antes os jogos da seleção brasileira de futebol eram capazes de parar o país, hoje muitos bares, restaurantes, shoppings, apresentam de forma ostensiva uma programação esportiva pela televisão. Parece ter havido uma adesão à "idéia" do esporte, ainda que seja necessária uma pesquisa séria de largo alcance para aferir os verdadeiros "hábitos esportivos" dos brasileiros. Mas o fato da gente comum andar pelas ruas com camisas de clubes - não só de futebol - com nomes de maionese, carros, sucos ou refrigerantes, a moda esportiva que praticamente se universalizou, mostram que parece ter sido um sucesso a campanha de "esclarecimento esportivo" iniciada durante a vigência da ditadura militar. E se entendermos que a política implica também a produção de determinado tipo de subjetividade acorde com imperativos políticos e econômicos contingentes historicamente, então podemos concluir que esporte e política durante a ditadura militar andaram sempre juntos no sentido de atender interesses diversos, nem sempre maniqueístas. O Brasil de fato se abriu para o mundo a partir dos anos 1970; realizações básicas, como a universalização da escola, ocorreram; a sociedade civil parece ter se fortalecido; avançou muito na arena esportiva internacional, para bem além do futebol. Continuamos não sendo uma potência esportiva, mas o esporte aqui é, de fato, um fenômeno popular massivo, pelo menos em relação a algumas modalidades. Enfim, o país parece ter realizado uma grande parte do seu projeto de modernização, ainda que de forma bastante conservadora e sem levar em conta as necessidades mais prementes da maior parte da sua população. A questão é perguntarmos pelo preço a pagar por essa forma de modernização e o seu alcance no médio e longo prazo para um país que continua longe de ser para todos. 
A idéia de um mundo acelerado, no qual devemos ser mais velozes e competitivos, que comporta uma preocupação hedônica e um novo higienismo, parece ser uma das tônicas da cultura das últimas quatro décadas do séc. XX. A qualidade de vida, um estilo de vida ativo, a afirmação do esporte e da indústria do entretenimento como expressão daquele estilo de vida, e todos os discursos politicamente corretos sustentam essas idéias, parecem fazer parte da cultura da era dos três mundos, expressão de Michael Denning (2005). Agregue-se a essas dimensões o fortalecimento do sentimento de brasilidade pelas realizações esportivas e termos o quadro do que significou a relação entre esporte, política e economia no Brasil, durante a ditadura militar. Entre a perspectiva naquilo que seria "nacional" e o alinhamento do país com uma cultura planetária, a ditadura militar foi responsável por estimular no Brasil o surgimento de um sentimento esportivo de massas, sem precedentes na história, se abstrairmos a experiência com o futebol. Desse modo, militares no poder parecem não ter grande originalidade no trato com o fenômeno esportivo. Mas tiveram o "mérito" de produzir as condições para o esporte, em todas as suas dimensões - da indústria ao espetáculo, da prática à contemplação esportiva - entrasse definitivamente na vida dos brasileiros. A começar pelos absurdos investimentos públicos diretamente ou indiretamente destinados ao esporte, hoje.

Dos culpados e inocentes de 1972 ao estilo de vida ativo prognosticado 15 anos depois, os agressivos esforços dos governos militares para popularizar o esporte deixam claro que a política se faz, sobretudo, ganhando a mente de uma determinada população. Não se trata de usar o esporte para amainar ímpetos revolucionários. Antes, se realizou um dos postulados do início do séc. XX: aquele de dotar uma população de capacidade de iniciativa, de atividade, capaz de sentir-se brasileira no êxito esportivo de alguns poucos indivíduos. Se isso significa o desenvolvimento de uma forma de política que homogeniza e remete ao pensamento único, só indagando com mais 
densidade esse fenômeno e a sua relação com a tradição autoritária da política brasileira poderemos ter uma noção mais consistente. Mas parte da resposta já foi ensaiada por Sidney Miller (1968):

No fim do mundo há um tesouro,

Quem for primeiro carrega o ouro.

A vida passa no meu cigarro,

quem tem mais pressa que arranje um carro

prá andar ligeiro sem ter porque.

Sem ter prá onde, pois é, pra que? 


\section{Sport and politics in the Brazilian military dictatorship: the creation of a national feeling of belonging through sports}

Abstract: This article investigates traces of the relation between sports and politics during the dictatorship which pervaded Brazil in the last decades of the twentieth century. Conspiracy theories are put aside, and focus is put on problematizing the fact that the sportive phenomenon, a hallmark of culture universalization, have fulfilled the dictatorship political purpose, without the dictatorship itself having propelled the sports as well. Firstly, it is demonstrated that the dictatorship was able to read the world context in order to appropriate and diffuse a practice with appeal to the masses and to consumerism, which led to new ways of subjectivation, thus affecting the interests and the needs of large portions of Brazilians. Sources used include, besides documents related to the sports universe, vestiges of the debate about the concept of "national" and "popular", a debate which marked the attempts of national affirmation.

Keywords: Sport and military dictatorship. sport and politics. history of sport. national and popular. mass culture.

\section{Deporte y politica en la dictadura military brasileña: la creacción de un pertenecimiento nacional deportivo}

Resumen: En el trabajo recojo huellas de la relación entre deporte y política em el período de la dictadura militar que afectó Brasil en las décadas finales del pasado siglo. Me alejo de explicaciones conspiratóiras y problematizo el hecho de que el fenômeno deportivo, rasgo de una cultura universalizada, há servido a los propósitos políticos de la dictadura, sin que haiga sido ella su propulsor. Por lo contrario argumento que la dictadura supo leer el contexto mundial para apropiarse y difundir una práctica de muy grande apello de mazas y consumo, que produjo nuevas formas de subjetivación, impactando asi lós intereses y las necesidades de grandes parcelas de la población brasileña. Utilizo como fuentes, ademas de documentos própios del universo deportivo, huellas del debate sobre lo que era nacional y lo popular, que enmarcó tentativas de afirmación de la nación.

Palavras-clave: deporte y dictadura militar. deporte y política. nacional y popular. cultura de mazas. 


\section{REFERÊNCIAS}

ARENDT, Hannah. Entre o passado e o futuro. São Paulo: Perspectiva, 2003.

BHABHA, Homi. O local da cultura. Belo Horizonte: Editora da UFMG, 1998.

CHAUÍ, Marilena. Cultura e democracia. São Paulo: Moderna, 1981.

DENNING, Michael. A cultura na era dos três mundos. São Paulo: Francis, 2005.

EDITORIAL. Revista Brasileira de Educação Física e Desportos, Brasília, n. 48, out./dez. 1981.

ESPORTE para todos. Revista Brasileira de Educação Física e Desportos, Brasília, n. 35, jul./dez. 1977.

FROMM, Erich. Abaixo à morte! Revista Civilização Brasileira, Rio de Janeiro, n. 14, jul. 1967.

MARQUES, Eric Tinoco. O tempo de colher. Revista Brasileira de Educação Física, Brasília, n. 12, 1972.

MILLER, Sidney. Brasil: do Guarani ao guaraná (LP). 1968.

. O universalismo e a música popular brasileira. Revista Civilização Brasileira, Rio de Janeiro, n. 21-22, set./dez. 1968.

RANGER, Terence; HOBSBAWM, Eric. A invenção das tradições. Rio de Janeiro: Paz e Terra, 1997.

SCHWARZ, Roberto. Cultura e política, São Paulo, 2001.

SOUZA, Ovídio. Munique 72: culpados e inocentes. Revista Brasileira de Educação Física, Brasília, n. 12, 1972.

WILLIAMS, Raymond. La larga revolución. Buenos Aires: Nueva Visión, 2005. 
